\title{
GEOMETRICAL EVALUATION OF RECTANGULAR FIN MOUNTED IN LATERAL SURFACE OF LID-DRIVEN CAVITY FORCED CONVECTIVE FLOWS
}

\author{
P. M. Rodrigues ${ }^{a}$, \\ E. S. Aldrighi ${ }^{a}$, \\ J. F. Prolo Filho ${ }^{b}$, \\ L. A. Isoldi ${ }^{\text {a }}$ \\ L. A. O. Rochac, \\ and E. D. dos Santos ${ }^{\mathrm{a}}$ \\ ${ }^{a}$ Universidade Federal do Rio Grande \\ Programa de Pós-Graduação em Modelagem \\ Computacional \\ Av. Itália, km 8, CEP. 96203-900, Rio Grande, \\ Rio Grande do Sul, Brasil \\ elizaldosantos@furg.br

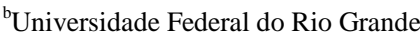 \\ Instituto de Matemática, Estatística e Física \\ Av. Itália, km 8, CEP. 96203-900, Rio Grande \\ Rio Grande do Sul, Brasi \\ ${ }^{\mathrm{c}}$ Universidade Federal do Rio Grande do Sul \\ Departamento de Engenharia Mecânica \\ Rua Sarmento Leite, 425, CEP 90050-170, \\ Porto Alegre, Rio Grande do Sul, Brasil \\ Received: Februry 15, 2019 \\ Revised: March 18, 2019 \\ Accepted: June 11, 2019
}

\section{ABSTRACT}

In this work, it is investigated the geometric effect of rectangular fin inserted in a lid-driven square cavity over thermal performance of laminar, incompressible, steady and forced convective flows. This study is performed by applying Constructal Design to maximize the heat transfer between the fin and the cavity flow. For that, the problem is subjected to two constraints: area of the cavity and area of rectangular fin, and two degrees of freedom: height/length ratio of rectangular fin $\left(\mathrm{H}_{1} / \mathrm{L}_{1}\right)$ and its position in upstream surface of the cavity $\left(S / \mathrm{A}^{1 / 2}\right)$. It is considered here some fixed parameters, as the ratio between the fin and cavity areas $(\varphi=$ $0.05)$, the aspect ratio of the cavity dimensions $(\mathrm{H} / \mathrm{L}=1.0)$ and Prandtl number $(\mathrm{Pr}=0.71)$. The fin aspect ratio $\left(\mathrm{H}_{1} / \mathrm{L}_{1}\right)$ was varied for three different placements of the fin at the upstream cavity surface $\left(S / \mathrm{A}^{1 / 2}=0.1\right.$, 0.5 and 0.9 ) which represents a lower, intermediate and upper positions of the fin. The effects of the fin geometry over the spatial-averaged Nusselt number $\left(\overline{\mathrm{Nu}_{\mathrm{H}}}\right)$ is investigated for three different Reynolds numbers $\left(\operatorname{Re}_{\mathrm{H}}=\right.$ $10,10^{2}$ and $10^{3}$ ). The conservation equations of mass, momentum and energy were numerically solved with the Finite Volume Method. Results showed that both degrees of freedom $\left(\mathrm{H}_{1} / \mathrm{L}_{1}\right.$ and $\left.\mathrm{S} / \mathrm{A}^{1 / 2}\right)$ had a strong influence over $\overline{\mathrm{Nu}_{\mathrm{H}}}$, mainly for higher magnitudes of Reynolds number. Moreover, the best thermal performance is reached when the fin is placed near the upper surface of the cavity for an intermediate ratio between height and length of rectangular fin, more precisely when $\left(\mathrm{S} / \mathrm{A}^{1 / 2}\right)_{0}=0.9$ and $\left(\mathrm{H}_{1} / \mathrm{L}_{1}\right)_{\text {oo }}=2.0$.

Keywords: constructal design; geometrical optimization; rectangular fin; forced convection; lid-driven cavity

\section{NOMENCLATURE}

A Area of the cavity [m²]

$\mathrm{A}_{1} \quad$ Area of the intruded fin [m²]

$\mathrm{C}_{\mathrm{p}} \quad$ Specific heat of the fluid [J/(kg.K)]

$\mathrm{H} \quad$ Height of the cavity [m]

$\mathrm{h} \quad$ Convective heat transfer coefficient $\left[\mathrm{W} /\left(\mathrm{m}^{2} \mathrm{~K}\right)\right]$

$\mathrm{H}_{1} \quad$ Height of the fin [m]

$\mathrm{k} \quad$ Thermal conductivity of the fluid $[\mathrm{W} /(\mathrm{m} . \mathrm{K})]$

$\mathrm{L} \quad$ Length of the cavity [m]

$\mathrm{L}_{1} \quad$ Length of the fin [m]

$\mathrm{Nu}_{\mathrm{H}} \quad$ Nusselt number based on cavity height, $\mathrm{hH} / \mathrm{k}$

P Pressure $\left[\mathrm{N} / \mathrm{m}^{2}\right]$

Pr Prandtl number, $v / \alpha$

$\mathrm{Re}_{\mathrm{H}} \quad$ Reynolds number based on height of the cavity, $\mathrm{u}_{\max } \mathrm{H} / \mathrm{v}$

$\mathrm{S}_{\mathrm{T}} \quad$ Surface area of integration

$\mathrm{T}$ Temperature [K]

$\mathrm{t} \quad$ Time [s]

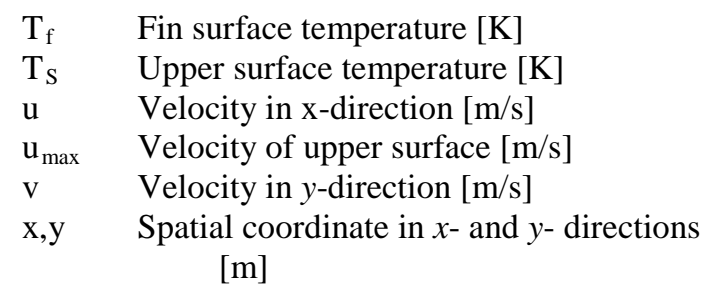

\section{Greek symbols}

$\alpha \quad$ Thermal diffusivity [ $\left.\mathrm{m}^{2} / \mathrm{s}\right]$

$v \quad$ Kinematic viscosity of the fluid $\left[\mathrm{m}^{2} / \mathrm{s}\right]$

$\rho \quad$ Density $\left[\mathrm{kg} / \mathrm{m}^{3}\right]$

$\Delta \mathrm{t} \quad$ Time-step $[s]$

$\mu \quad$ Dynamic viscosity of the fluid $[\mathrm{kg} /(\mathrm{m} . \mathrm{s})]$

$\Omega \quad$ Spatial domain

$\varphi \quad$ Fraction area of the fin, $\mathrm{A}_{1} / \mathrm{A}$

\section{Subscripts/Superscripts}

$\begin{array}{ll}\mathrm{m} & \text { Once maximized } \\ \mathrm{mm} & \text { Twice maximized }\end{array}$ 


$\begin{array}{ll}\begin{array}{l}\text { o } \\ \text { oo } \\ \max \end{array} & \begin{array}{l}\text { Once optimized } \\ \text { Twice optimized } \\ \text { Maximal velocity or temperature inside the } \\ \text { cavity domain }\end{array} \\ \text { min } & \begin{array}{l}\text { Minimal temperature inside the cavity } \\ \text { domain }\end{array} \\ 1 & \begin{array}{l}\text { Fin variable } \\ *\end{array} \\ - & \begin{array}{l}\text { Dimensionless variables } \\ \text { Spatial-averaged variables }\end{array}\end{array}$

\section{INTRODUCTION}

Convective cavity flows represent ideally several engineering problems as those found in electronic packaging, spacing between fins in heat exchangers, solar air heater (SAC) and HVAC devices (Fontana et al., 2015). Moreover, the simplicity of domain and the presence of complex phenomena such as boundary detachment and reattachment, generation of primary and secondary vortices make the cavity problem interesting for several experimental and numerical works (Prasad and Koseff, 1989; Prasad and Koseff, 1996; Erturk and Gökçol, 2006; Dos Santos et al., 2011; Gibanov et al., 2017).

As a consequence, many studies have been performed to improve the knowledge about fluid dynamic and thermal patterns of forced and mixed convective flows inside cavities (Lin et al., 2011; Sivasankaran et al., 2013; Dos Santos et al., 2013a; Kareem et al., 2016). Concerning the intrusion of fins or obstacles in lid-driven cavity flows, important advances have been performed. For instance, Chamkha et al. (2011) investigated mixed convective flows in a cavity with heated square cylinder inserted in the cavity center. The velocity and thermal fields were studied for different geometries of cavity. The influence of Reynolds and Richardson numbers over the flow patterns was also analyzed. Recently, Hammami et al. (2017) carried out a numerical investigation about two-sided lid-driven cubical cavity induced by a cylindrical shape at the center. It was investigated different Reynolds numbers in the range (100 $\leq \square \operatorname{Re} \square \leq \square 1500$ ) seeking to investigate the Reynolds number where a transition from steady to unsteady state occurs. Afterwards, Gibanov et al. (2017) investigated a conjugate heat transfer by mixed convection in a cavity with a conductive heat transfer in a heated solid intruded in the cavity. Considering that the study of bodies and fins intruded in cavity convective flows is an important issue, the geometrical evaluation of intruded fin in lid-driven cavity flow is also an important subject.

Constructal Design has also been employed for geometrical evaluation of this kind of problem. Constructal Design is a method based in the physical principle denominated Constructal Law of design and evolution (Bejan, 2000; Bejan and Lorente, 2008; Bejan and Zane, 2012, Bejan, 2016). According to this law, any flow system (animated or inanimated) of finite dimensions, to persist in time (to survive), must evolve its design to easily the internal streams that flow through it (Bejan and Lorente, 2008; Bejan, 2016). Many recommendations about designs in several engineering problems have been achieved with Constructal Design, e.g., convective internal and external flows, heat generating solids with intruded cavities, renewable energy and solid mechanics (Barros et al., 2017; Lorenzini et al., 2014; Xie et al., 2015; Lorenzini et al., 2017; Helbig et al., 2016; Rodrigues et al., 2015; Vieira et al., 2017).

Constructal Design has recently been employed for investigation of fins intruded in forced and mixed convective lid-driven cavity flows. One of the pioneer works was performed by Dos Santos et al. (2013b), which evaluated the geometry of a rectangular fin inserted into the bottom wall of the cavity seeking to maximize the heat exchange between the fin and surrounding forced convective flow. The effect of Reynolds number over the design was also evaluated for a constant Prandtl number (Pr $=0.71$ ). Lorenzini et al. (2016) investigated a similar configuration, but took into account mixed convective flows, studying the effects of Reynolds and Rayleigh numbers over design of the problem. Aldrighi et al. (2016) investigated forced convective flows in lid-driven cavities with intruded rectangular fins. However, three different placements of the fin mounted in cavity surfaces are investigated (lower, upstream and downstream surfaces). More recently, Razera et al. (2016) evaluated mixed convective flows in lid-driven cavities considering triangular fin inserted in its bottom surface.

In the present work, it is proposed the geometrical evaluation of forced convective flow in a lid-driven square cavity with inserted rectangular fin in upstream surface of the cavity. It is evaluated the effect of aspect ratio between the height and length of the fin $\left(\mathrm{H}_{1} / \mathrm{L}_{1}\right)$ for three different placements of the fin mounted in the upstream surface $\left(\mathrm{S} / \mathrm{A}^{1 / 2}=0.1,0.5\right.$ and 0.9 ) over the thermal performance of the cavity. The influence of different Reynolds numbers $\left(\operatorname{Re}_{\mathrm{H}}=\right.$ $10,10^{2}$ and $10^{3}$ ) is also performed. For all simulations, it is considered a constant fraction area of the fin (

The forced convective flow is considered twodimensional, laminar, incompressible and at steady state. Then, conservation equations of mass, momentum and energy are numerically solved with the Finite Volume Method, more precisely with commercial code FLUENT (FLUENT, 2007; Versteeg and Malalasekera, 2007).

\section{MATHEMATICAL MODELLING}

The differential equations that describe the conservation of mass, momentum and energy for a two-dimensional lid-driven cavity flow problem in steady and forced convective regimes, considering a incompressible fluid with constant thermal physical properties are given by Bejan (2013): 


$$
\begin{gathered}
\frac{\partial u}{\partial \mathrm{x}}+\frac{\partial \mathrm{v}}{\partial \mathrm{y}}=0 \\
\left(\mathrm{u} \frac{\partial \mathrm{u}}{\partial \mathrm{x}}+\mathrm{v} \frac{\partial \mathrm{u}}{\partial \mathrm{y}}\right)+\frac{1}{\rho} \frac{\partial \mathrm{P}}{\partial \mathrm{x}}-\mathrm{v}\left(\frac{\partial^{2} \mathrm{u}}{\partial \mathrm{x}^{2}}+\frac{\partial^{2} \mathrm{u}}{\partial \mathrm{y}^{2}}\right)=0 \\
\left(\mathrm{u} \frac{\partial \mathrm{v}}{\partial \mathrm{x}}+\mathrm{v} \frac{\partial \mathrm{v}}{\partial \mathrm{y}}\right)+\frac{1}{\rho} \frac{\partial \mathrm{P}}{\partial \mathrm{y}}-\mathrm{v}\left(\frac{\partial^{2} \mathrm{v}}{\partial \mathrm{x}^{2}}+\frac{\partial^{2} \mathrm{v}}{\partial \mathrm{y}^{2}}\right)=0 \\
\left(\mathrm{u} \frac{\partial \mathrm{T}}{\partial \mathrm{x}}+\mathrm{v} \frac{\partial \mathrm{T}}{\partial \mathrm{y}}\right)-\alpha\left(\frac{\partial^{2} \mathrm{~T}}{\partial \mathrm{x}^{2}}+\frac{\partial^{2} \mathrm{~T}}{\partial \mathrm{y}^{2}}\right)=0
\end{gathered}
$$

where $\mathrm{u}$ and $\mathrm{v}$ are the velocities in $\mathrm{x}$ - and $\mathrm{y}$ directions; $\rho$ is the fluid density; $P$ is the pressure; $v$ is the kinematic viscosity of the fluid $(\mu / \rho) ; \alpha$ is the thermal diffusivity $\left(\mathrm{k} / \rho \mathrm{C}_{\mathrm{p}}\right)$ and $\mathrm{T}$ is the temperature.

\section{PROBLEM DESCRIPTION}

The class of problems to be studied here consists of a permanent laminar flow with forced convective heat transfer in a lid-driven square cavity of dimensions: $\mathrm{H}=\mathrm{L}=1.0 \mathrm{~m}$ (or $\mathrm{H}^{*}=\mathrm{L}^{*}=1.0$ ), Fig. 1, considering constant thermophysical properties. Inside, there is a rectangular fin, inserted in the upstream surface at position $S / A^{1 / 2}$ of the cavity, whose geometry is varied according to Constructal Design method.

The fluid flow is caused by the continuous motion of an infinite plate that also represents the upper surface, where its velocity is used as a reference for calculating the Reynolds number $\left(\mathrm{Re}_{\mathrm{H}}\right)$ in terms of the height of the cavity $(\mathrm{H})$.

In the other surfaces, the dimensionless velocities are considered null $\left(\mathrm{u}^{*}=\mathrm{v}^{*}=0\right)$ and have non-slip and impermeability boundary conditions. For the thermal field, a dimensionless temperature of $\mathrm{T}^{*}=1.0$ is applied to the fin surfaces for heating the flow, whereas the upper surface has a dimensionless temperature $\left(\mathrm{T}^{*}=0.0\right)$. For heat transfer, the dashed surfaces are considered adiabatic, while the upper surface of the cavity and the surfaces of the fin receive temperatures, respectively, $T_{\mathrm{s}}=300 \mathrm{~K}$ and $\mathrm{T}_{\mathrm{f}}$ $=320 \mathrm{~K}$.

The equations of the problem are totally in the dimensionless form. In this way, is defined

$$
\begin{gathered}
\mathrm{x}^{*}, \mathrm{y}^{*}, \mathrm{H}^{*}, \mathrm{~L}^{*}, \mathrm{H}_{1}{ }^{*}, \mathrm{~L}_{1}^{*}=\frac{\mathrm{x}, \mathrm{y}, \mathrm{H}, \mathrm{L}, \mathrm{H}_{1}, \mathrm{~L}_{1}}{\mathrm{~A}^{1 / 2}} \\
\mathrm{u}^{*}, \mathrm{v}^{*}=\frac{\mathrm{u}, \mathrm{v}}{\mathrm{u}_{\max }} \\
\mathrm{T}^{*}=\frac{\mathrm{T}-\mathrm{T}_{\min }}{\mathrm{T}_{\max }-\mathrm{T}_{\min }}
\end{gathered}
$$

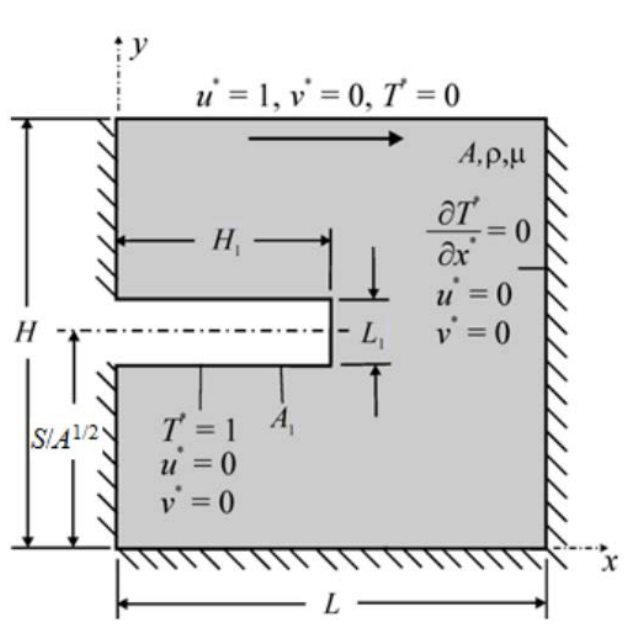

Figure 1. Problem domain for lid-driven cavity flow with inserted rectangular fin on upstream surface.

as the dimensionless versions of spatial coordinates, velocities and temperature. For the geometric evaluation of the problem by the Constructal Design method, the areas of the cavity and the fin are calculated, respectively, by

$$
\begin{gathered}
\mathrm{A}=\mathrm{HL} \\
\mathrm{A}_{1}=\mathrm{H}_{1} \mathrm{~L}_{1}
\end{gathered}
$$

and the ratio between the fin and cavity areas is estimated by

$$
\phi=\frac{\mathrm{A}_{1}}{\mathrm{~A}}
$$

In this study, the ratio between the fin and cavity areas ( che-10:Q5x)landmber $(\mathrm{Pr}=$ 0.71 ) are considered fixed and the cavity geometry ratio $(\mathrm{H} / \mathrm{L}=1.0)$. The problem is subjected to two degrees of freedom $\left(\mathrm{H}_{1} / \mathrm{L}_{1}\right.$ and $\left.\mathrm{S} / \mathrm{A}^{1 / 2}\right)$. The ratio $\mathrm{H}_{1} / \mathrm{L}_{1}$ is varied for three different magnitudes of $\mathrm{S} / \mathrm{A}^{1 / 2}=0.1,0.5$ and 0.9. Moreover, three different values of Reynolds number was investigated $\left(\mathrm{Re}_{\mathrm{H}}=\right.$ $10,10^{2}$ and $10^{3}$ ). The main purpose is to maximize the heat transfer between the fin and the flow in the cavity (indicated by the Nusselt number).

The Nusselt number indicates the magnitude of convection heat transfer between the fin and the circulating flow and is given by

$$
\mathrm{Nu}_{\mathrm{H}}=\frac{\mathrm{hH}}{\mathrm{k}}=\frac{\partial \mathrm{T}^{*}}{\partial \mathrm{n}^{*}}
$$

where $\mathrm{h}$ is the heat transfer coefficient and $\mathrm{n}$ represents a normal coordinate to the fin surface. In order to compare the different geometries investigated, it is used the spatial-averaged Nusselt number, which is defined by 


$$
\overline{\mathrm{Nu}_{\mathrm{H}}}=\frac{1}{\mathrm{~S}_{\mathrm{T}}} \int_{\mathrm{S}_{\mathrm{T}}} \mathrm{Nu}_{\mathrm{H}} \mathrm{dS}
$$

where $\mathrm{Nu}_{\mathrm{H}}$ is the local Nusselt number in terms of the height of the cavity and $\mathrm{S}_{\mathrm{T}}$ is the surface area of integration.

In the present work, it is employed Constructal Design method associated with exhaustive search to seek for the optimal shapes. As can be seen in flowchart of Figure 2, the evaluation process is shared in three steps. Firstly, the fin geometry is optimized by varying the ratio $\mathrm{H}_{1} / \mathrm{L}_{1}$ and calculating the Nusselt number, keeping fixed the other degrees of freedom $\left(\mathrm{S} / \mathrm{A}^{1 / 2}\right)$ and Reynolds number constant. Thus, the Nusselt number once maximized, $\mathrm{Nu}_{\mathrm{H}, \mathrm{m}}$, is defined as the highest magnitude of the Nusselt number, and the correspondent ratio $\mathrm{H}_{1} / \mathrm{L}_{1}$ is called once optimized ratio $\left(\mathrm{H}_{1} / \mathrm{L}_{1}\right)_{0}$.

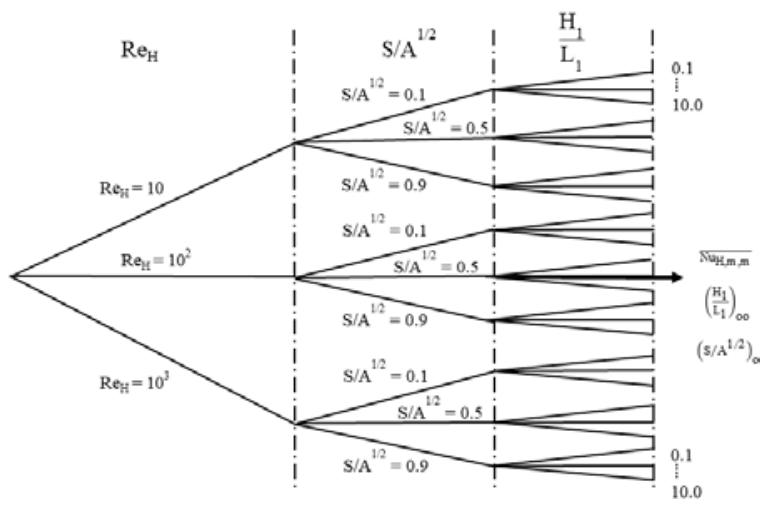

Figure 2. Flowchart of performed simulations.

In the second step, the same process performed in step 1 is repeated for other positions of fin $\left(S / A^{1 / 2}\right)$ and maintaining the Reynolds number constant. The highest Nusselt number achieved is named $\mathrm{Nu}_{\mathrm{H}, \mathrm{mm}}$ $\left(\mathrm{Nu}_{\mathrm{H}}\right.$ twice maximized), and the corresponding optimal shapes are $\left(\mathrm{H}_{1} / \mathrm{L}_{1}\right)_{\text {oo }}\left(\mathrm{H}_{1} / \mathrm{L}_{1}\right.$ ratio twice optimized) and $\left(\mathrm{S} / \mathrm{A}^{1 / 2}\right)_{0}$ (position $\mathrm{S} / \mathrm{A}^{1 / 2}$ once optimized).

Finally, the third step is repeated for different evaluated Reynolds numbers $\left(\operatorname{Re}_{H}\right)$. For the geometrical evaluation performed here, a total of 176 simulated cases to examine all possible configurations were required. At this point, the spatial-averaged Nusselt number two times maximized $\left(\overline{\mathrm{Nu}_{\mathrm{H}, \mathrm{mm}}}\right)$ and the respective optimal shapes, $\left(\mathrm{S} / \mathrm{A}^{1 / 2}\right)_{0}$ and $\left(\mathrm{H}_{1} / \mathrm{L}_{1}\right)_{\mathrm{oo}}$, are reached.

\section{NUMERICAL MODELING}

In the preprocessing stage, a computational mesh based on rectangular volumes is generated using the GAMBIT software (Fluent, 2007), in which the domain is discretized in finite rectangular volumes. The conservation equations of mass, momentum and energy, Eqs. (1) - (4), are tackled with Finite Volume Method (FVM) through the use of commercial software FLUENT (FLUENT, 2007; Versteeg and Malalasekera, 2007), in which different configurations of the fin are tested, such as the proportion $\mathrm{H}_{1} / \mathrm{L}_{1}$ and the position $\left(\mathrm{S} / \mathrm{A}^{1 / 2}\right)$, for different Reynolds values $\left(\operatorname{Re}_{\mathrm{H}}\right)$.

Concerning the numerical procedures for solving the conservation equations, SIMPLEC (SemiImplicit Method for Pressure-Linked EquationsConsistent) algorithm is used for velocity-pressure coupling. The first-order Upwind interpolation scheme is used to treat the dominant advective terms for momentum and energy equations. In addition, it is considered that the convergence is reached when residuals for mass, momentum and energy between two consecutive iterations are smaller than $10^{-6}, 10^{-6}$ and $10^{-8}$, respectively.

In order to validate the present numerical methodology, velocity and temperature profiles were generated for a classical case of a forced convective flow in a lid-driven square cavity without fins. It is considered a steady state forced convective flow. Results obtained with the present method are compared with those obtained in literature.

In this particular case, the fluid motion is caused only by velocity imposition in the upper surface of the cavity, while in the other surfaces the velocity is null. In the thermal field, the heat transfer is due to the temperature difference between the upper surface and the other ones. As a boundary condition, the highest temperature $\left(\mathrm{T}^{*}=1.0\right)$ is imposed on the upper surface while the lowest temperature is maintained on the lower surface $\left(\mathrm{T}^{*}=0.0\right)$. To describe the flow, we also assigned $\mathrm{Re}_{\mathrm{H}}=100$ and $\mathrm{Pr}$ $=0.71$.

In this analysis, a section of the cavity was chosen, where $x^{*}=0.5$ and the results were compared with those obtained by Dos Santos et al. (2013b) and Nallasamy and Prasad (1977) for the velocity profiles (Figure 3a) and temperature profiles (Figure 3b). Due to the good agreement of the results presented, this numerical method is considered suitable for subsequent study and geometrical evaluation of forced convective lid-driven cavity flow with inserted fins. All simulations performed here were obtained when an independent grid was reached as described by Dos Santos et al. (2013b), using $100 \times 100$ rectangular volumes in $\mathrm{x}$ - and $\mathrm{y}$ - directions.

In addition, results obtained by the present model at steady state are comparable with those presented by Aldrighi et al. (2016) for different values of $\mathrm{Re}_{\mathrm{H}}$ for fins positioned in $\mathrm{S} / \mathrm{A}^{1 / 2}=0.5$ of the upstream cavity surface.

\section{RESULTS AND DISCUSSION}

Firstly, it is performed the variation of the ratio $\mathrm{H}_{1} / \mathrm{L}_{1}$ to evaluate its effect over the spatial-averaged Nusselt number $\left(\overline{\mathrm{Nu}_{\mathrm{H}}}\right)$.

The fins were inserted at different positions of 
the upstream surface of the cavity, S/A ${ }^{1 / 2}=0.1,0.5$ and 0.9 and a range of the fin size variation ratio was established, $0.1 \leq \mathrm{H}_{1} / \mathrm{L}_{1} \leq 10.0$. Due to cavity domain strapolation, when $\mathrm{S} / \mathrm{A}^{1 / 2}=0.1$ and 0.9 , the fin geometric ratio had to be changed to $2.0 \leq \mathrm{H}_{1} / \mathrm{L}_{1}$ $\leq 10.0$.

In addition, the gain in the convective heat transfer rate between the fin and the flow with the increase of Reynolds number $\left(\operatorname{Re}_{\mathrm{H}}\right)$ was evaluated, considering the optimal fin geometries $\left(\left(\mathrm{S} / \mathrm{A}^{1 / 2}\right)_{0}\right.$ and $\left.\left(\mathrm{H}_{1} / \mathrm{L}_{1}\right)_{\mathrm{oo}}\right)$.
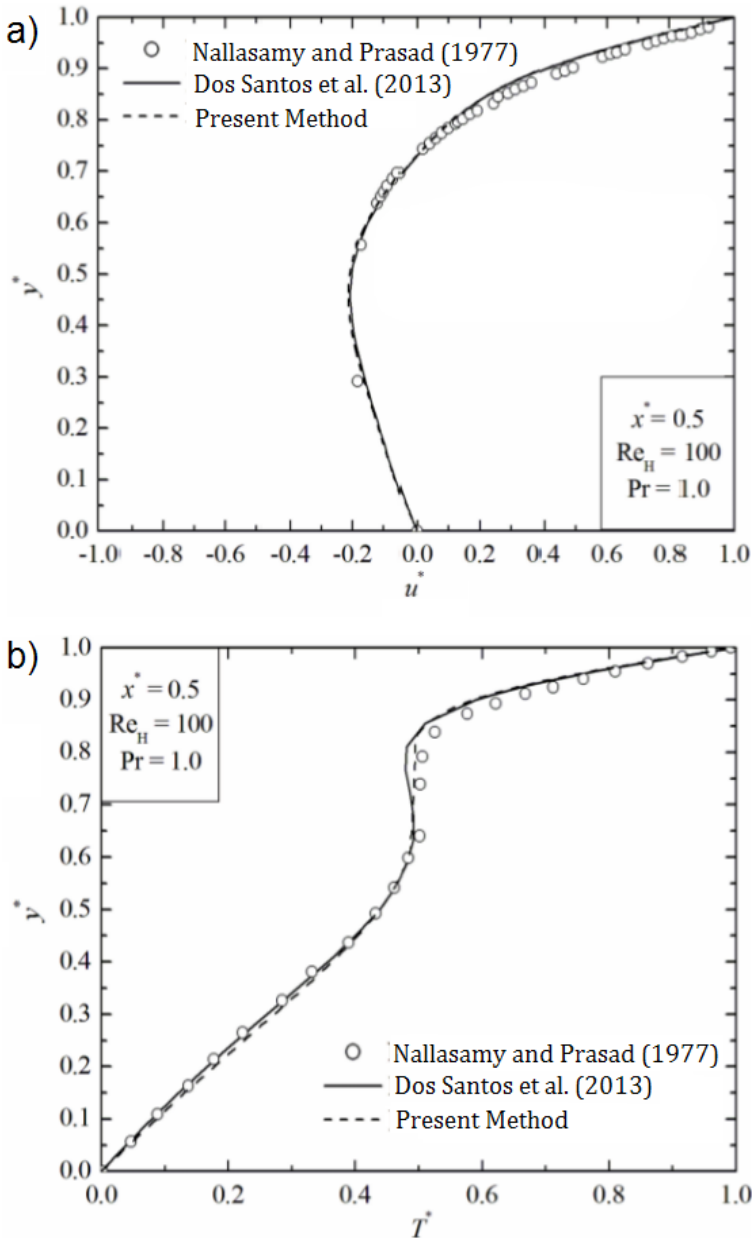

Figure 3. Time-averaged dimensionless profiles for forced convective flow with $\operatorname{Re}_{\mathrm{H}}=100$ and $\operatorname{Pr}=1.0$ :

a) velocity profile in $x^{*}$ direction at $x^{*}=0.5$; b) temperature profile at $x^{*}=0.5$.

First of all, as can be seen in Figures 4 and 5, the $\mathrm{H}_{1} / \mathrm{L}_{1}$ ratio shows lower influence on $\overline{\mathrm{Nu}_{\mathrm{H}}}$ for the lowest magnitude of $\operatorname{Re}_{\mathrm{H}}\left(\operatorname{Re}_{\mathrm{H}}=10.0\right)$ for fins placed in the lower positions $\left(\mathrm{S} / \mathrm{A}^{1 / 2}=0.1\right.$ and 0.5$)$.

As expected, when increases the $\mathrm{Re}_{\mathrm{H}}$ value, the spatial-averaged Nusselt number value also increases. However, higher $\mathrm{H}_{1} / \mathrm{L}_{1}$ ratios may contribute to worsening the heat exchange performance of the thermal system, contrarily to the common sense where it is expected that the augmentation of heat transfer area led to a maximization of thermal performance.

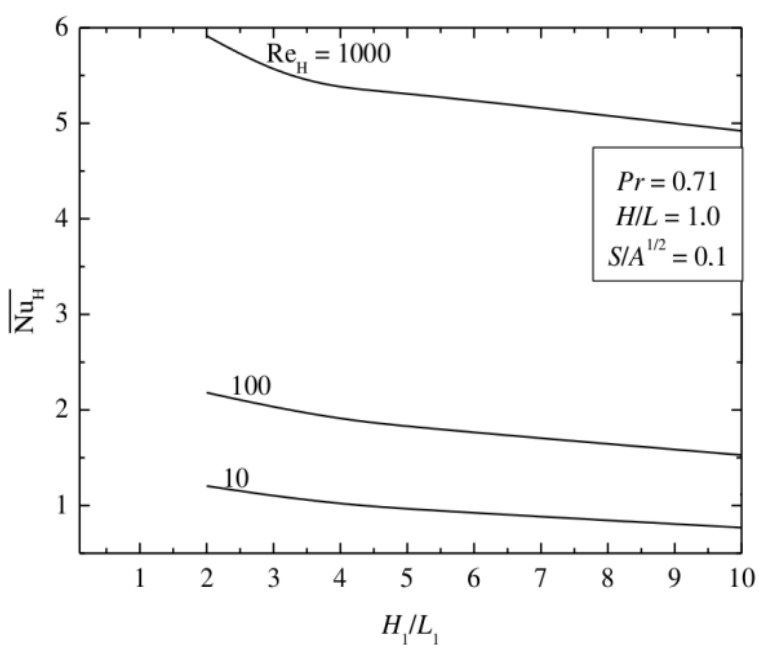

Figure 4. Effect of the ratio $\mathrm{H}_{1} / \mathrm{L}_{1}$ over Nusselt number $\left(\overline{\mathrm{Nu}_{\mathrm{H}}}\right)$ for various Reynolds numbers $\left(\mathrm{Re}_{\mathrm{H}}\right)$ for the fin intruded in the upstream surface at $S / A^{1 / 2}=$ 0.1 .

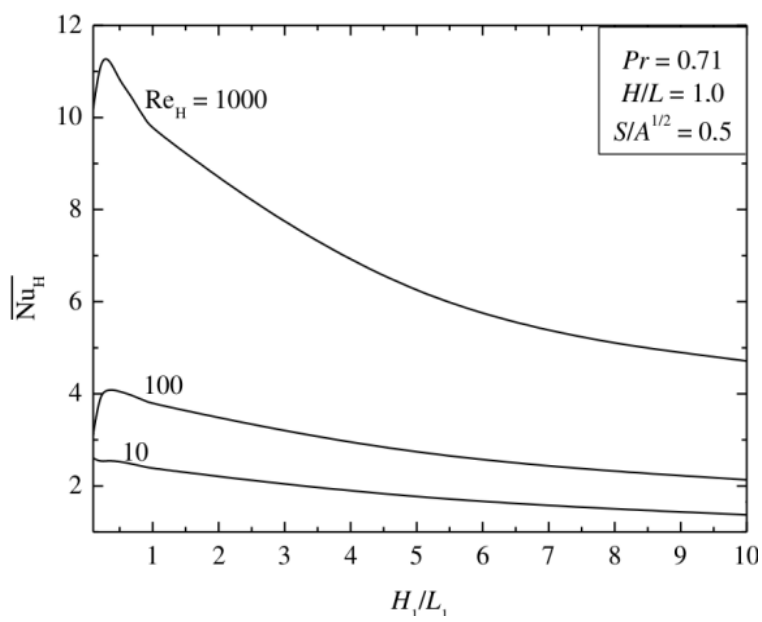

Figure 5. Effect of the ratio $\mathrm{H}_{1} / \mathrm{L}_{1}$ over Nusselt number $\left(\overline{\mathrm{Nu}_{\mathrm{H}}}\right)$ for various Reynolds numbers $\left(\mathrm{Re}_{\mathrm{H}}\right)$ for the fin intruded in the upstream surface at $\mathrm{S} / \mathrm{A}^{1 / 2}=$ 0.5 .

The fin position inside the cavity is also a determining factor for the heat exchange efficiency. It can be observed that for a same $\mathrm{H}_{1} / \mathrm{L}_{1}$ ratio, fins positioned closer the upper surface (Figure 6) have the best thermal performance among the evaluated fin placements, even for low $\mathrm{Re}_{\mathrm{H}}$.

In order to evaluate the geometry influence also in the thermal field, Figs. 7, 8 and 9 are presented, showing the profiles obtained by the fin insertion at $\mathrm{S} / \mathrm{A}^{1 / 2}=0.1,0.5$ and 0.9 positions of the upstream cavity. For each one of these positions, the flow are evaluated for $\mathrm{Re}_{\mathrm{H}}=10,100$ and 1000 and are identified the best (items a, c, e) and worst (items b, $\mathrm{d}, \mathrm{f})$ fins configurations. The red color represents the highest temperatures (warmer), while the blue one represents the lower (colder) temperatures. 


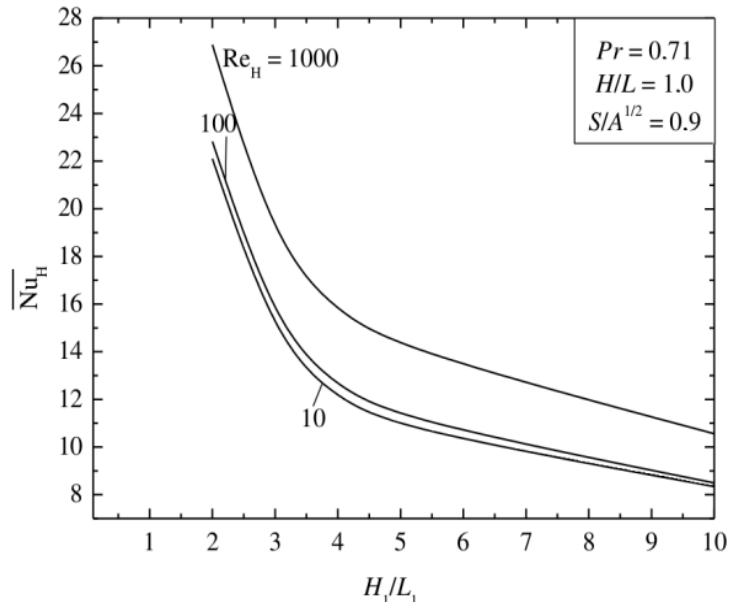

Figure 6. Effect of the ratio $\mathrm{H}_{1} / \mathrm{L}_{1}$ over Nusselt number $\left(\overline{\mathrm{Nu}_{\mathrm{H}}}\right)$ for various Reynolds numbers $\left(\mathrm{Re}_{\mathrm{H}}\right)$ for the fin intruded in the upstream surface at $S / A^{1 / 2}=$ 0.9 .

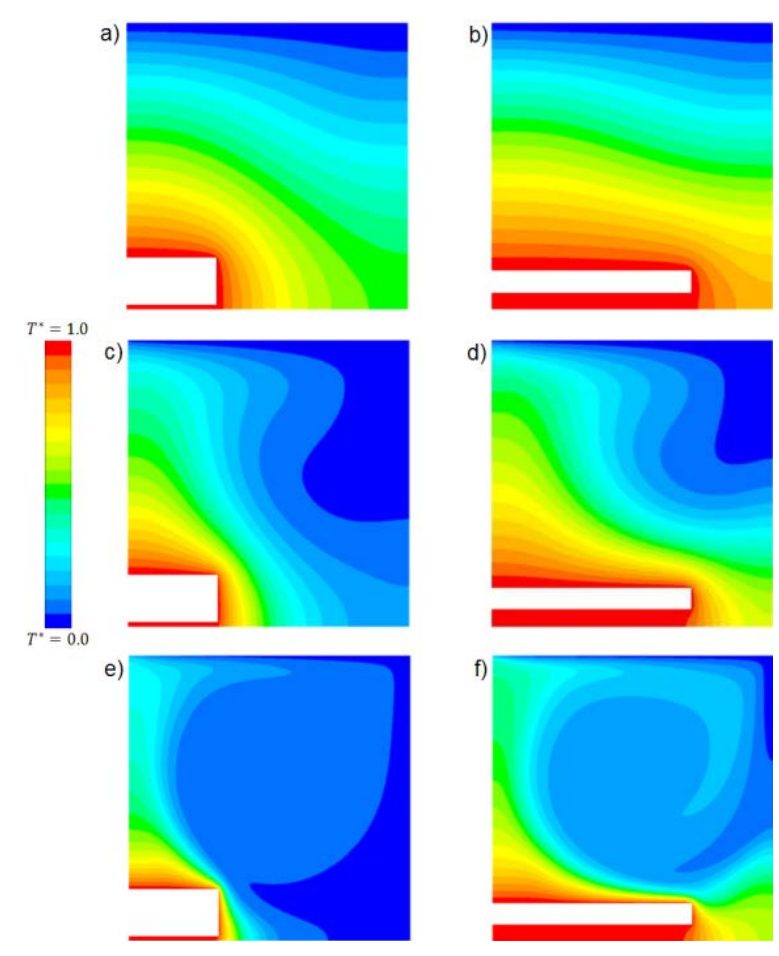

Figure 7. Temperature field obtained for different $\mathrm{Re}_{\mathrm{H}}$, considering the fin inserted at $S / \mathrm{A}^{1 / 2}=0.1$ of the upstream surface of the cavity, with $\mathrm{H} / \mathrm{L}=1.0$ :

a) $\mathrm{Re}_{\mathrm{H}}=10, \overline{\mathrm{Nu}_{\mathrm{H}, \mathrm{m}}}=1.2048,\left(\mathrm{H}_{1} / \mathrm{L}_{1}\right)_{\mathrm{o}}=2.0$;

b) $\mathrm{Re}_{\mathrm{H}}=10, \overline{\mathrm{Nu}_{\mathrm{H}}}=0.7687, \mathrm{H}_{1} / \mathrm{L}_{1}=10.0$;

c) $\mathrm{Re}_{\mathrm{H}}=100, \overline{\mathrm{Nu}_{\mathrm{H}, \mathrm{m}}}=2.1817,\left(\mathrm{H}_{1} / \mathrm{L}_{1}\right)_{\mathrm{o}}=2.0$;

d) $\mathrm{Re}_{\mathrm{H}}=100, \overline{\mathrm{Nu}_{\mathrm{H}}}=1.5228, \mathrm{H}_{1} / \mathrm{L}_{1}=10.0$;

e) $\mathrm{Re}_{\mathrm{H}}=1000, \overline{\mathrm{Nu}_{\mathrm{H}, \mathrm{m}}}=5.9135,,\left(\mathrm{H}_{1} / \mathrm{L}_{1}\right)_{\mathrm{o}}=2.0$;

f) $\mathrm{Re}_{\mathrm{H}}=1000, \overline{\mathrm{Nu}_{\mathrm{H}}}=4.9200, \mathrm{H}_{1} / \mathrm{L}_{1}=10.0$.

Based on this color pattern and the $\overline{\mathrm{Nu}_{\mathrm{H}}}$ values obtained in the process, it can be seen that geometries with higher concentrations of red (hot) areas have worse thermal performance, indicating that the optimal geometry in fact depends on the position in which the fin is inserted into the cavity, as well as the
Reynolds number.

For small values of $\operatorname{Re}_{\mathrm{H}}\left(\mathrm{Re}_{\mathrm{H}}=10\right)$, the isothermals are smooth curves and the circulations generated inside the cavity have low intensity (Figs. 7, 8 and 9, items a, b).

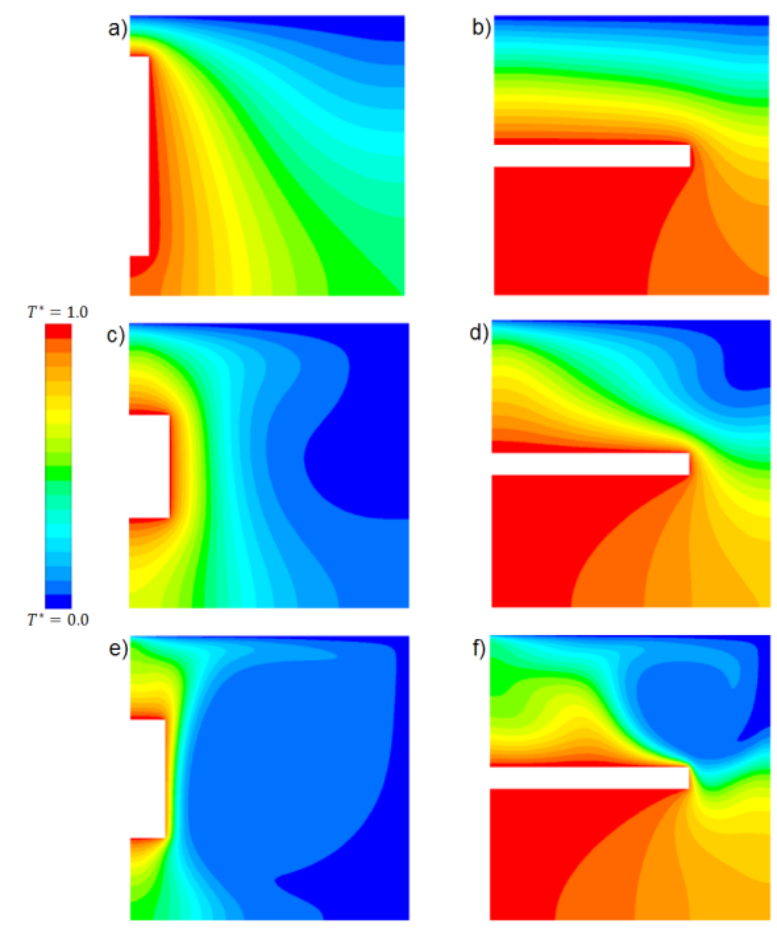

Figure 8. Temperature field obtained for different $\mathrm{Re}_{\mathrm{H}}$, considering the fin inserted at $\mathrm{S} / \mathrm{A}^{1 / 2}=0.5$ of the upstream surface of the cavity with $\mathrm{H} / \mathrm{L}=1.0$ :

a) $\operatorname{Re}_{\mathrm{H}}=10, \overline{\mathrm{Nu}_{\mathrm{H}, \mathrm{m}}}=2.6035,\left(\mathrm{H}_{1} / \mathrm{L}_{1}\right)_{\mathrm{o}}=0.1$;

b) $\mathrm{Re}_{\mathrm{H}}=10, \overline{\mathrm{Nu}_{\mathrm{H}}}=1.3717, \mathrm{H}_{1} / \mathrm{L}_{1}=10.0$;

c) $\mathrm{Re}_{\mathrm{H}}=100, \overline{\mathrm{Nu}} \mathrm{H,m}=4.0887,\left(\mathrm{H}_{1} / \mathrm{L}_{1}\right)_{\mathrm{o}}=0.4$;

d) $\mathrm{Re}_{\mathrm{H}}=100, \overline{\mathrm{Nu}_{\mathrm{H}}}=2.1340, \mathrm{H}_{1} / \mathrm{L}_{1}=10.0$;

e) $\mathrm{Re}_{\mathrm{H}}=1000, \overline{\mathrm{Nu}_{\mathrm{H}, \mathrm{m}}}=11.3283,\left(\mathrm{H}_{1} / \mathrm{L}_{1}\right)_{\mathrm{o}}=0.3$;

f) $\mathrm{Re}_{\mathrm{H}}=1000, \overline{\mathrm{Nu}_{\mathrm{H}}}=4.7126, \mathrm{H}_{1} / \mathrm{L}_{1}=10.0$.

When the $\mathrm{Re}_{\mathrm{H}}$ increases to 100 , it can be seen in the optimal configurations (Figs. 7c, 8c and 9c) that intensity of main vortex also increases and, as a consequence, the cold flow circulation reaches the fin and cavity surfaces, facilitating the heat exchange.

The largest magnitudes of $\overline{\mathrm{Nu}_{\mathrm{H}}}$ are obtained for $\mathrm{Re}_{\mathrm{H}}=1000$. Following the temperature gradients, it is observed that, among the cases studied, the ideal geometry corresponds to the fin with ratio $\left(\mathrm{H}_{1} / \mathrm{L}_{1}\right)_{\text {oo }}$ $=2.0$, positioned at $\left(\mathrm{S} / \mathrm{A}^{1 / 2}\right)_{0}=0.9$ (Figure $\left.9 \mathrm{e}\right)$. This is because, even having a relatively narrow contact surface, it does not obstruct the cavity circulation, providing a more effective heat exchange. It's also observed that the higher Reynolds number caused an asymmetric behavior in the temperature gradient, concentrating the circulations in the upper right corner of the cavity.

A qualitative study can be done regarding the relative difference between $\overline{\mathrm{Nu}_{\mathrm{H}, \mathrm{m}}}$ (best) and $\overline{\mathrm{Nu}_{\mathrm{H}}}$ (worst), based on the geometric configurations 
used in the systems, for each value of $\mathrm{Re}_{\mathrm{H}}$ and at each position where the fin is inserted (Tab. 1).

Table 1. Relative difference between $\overline{\mathrm{Nu}_{\mathrm{H}, \mathrm{m}}}$ and $\overline{\mathrm{Nu}_{\mathrm{H}}}$ varying the fin position and $\mathrm{Re}_{\mathrm{H}}$.

\begin{tabular}{|c|c|c|c|}
\hline $\mathrm{Re}_{\mathrm{H}} \mathrm{S} / \mathrm{A}^{1 / 2}$ & 0.1 & 0.5 & 0.9 \\
\hline 10 & $36 \%$ & $47 \%$ & $62 \%$ \\
\hline 100 & $30 \%$ & $47 \%$ & $62 \%$ \\
\hline 1000 & $16 \%$ & $58 \%$ & $60 \%$ \\
\hline
\end{tabular}

Table 1 shows that the relative difference between the best and the worst $\overline{\mathrm{Nu}_{\mathrm{H}}}$ has an almost constant tendency for small values of $\mathrm{Re}_{\mathrm{H}}$. This behavior was already expected due to the profiles proximity shown in Figures 4-6 for $\mathrm{Re}_{\mathrm{H}} \leq 100$. However, for $\mathrm{Re}_{\mathrm{H}}=1000$ this tendency changes and is basically caused by the fluid condition in the vicinity of the fin.

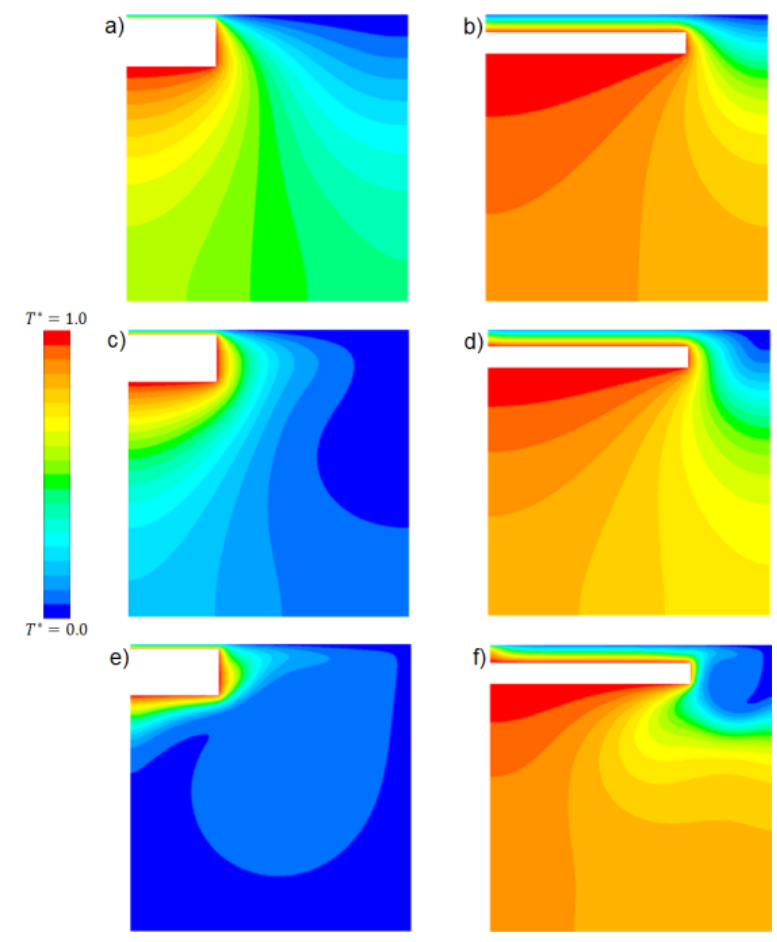

Figure 9. Temperature field obtained for different $\mathrm{Re}_{\mathrm{H}}$, considering the fin inserted at $\mathrm{S} / \mathrm{A}^{1 / 2}=0.9$ of the upstream surface of the cavity with $\mathrm{H} / \mathrm{L}=1.0$ :

a) $\mathrm{Re}_{\mathrm{H}}=10, \overline{\mathrm{Nu}_{\mathrm{H}, \mathrm{m}}}=22.1034,\left(\mathrm{H}_{1} / \mathrm{L}_{1}\right)_{\mathrm{o}}=2.0$;

b) $\mathrm{Re}_{\mathrm{H}}=10, \overline{\mathrm{Nu}_{\mathrm{H}}}=8.3421, \mathrm{H}_{1} / \mathrm{L}_{1}=10.0$;

c) $\mathrm{Re}_{\mathrm{H}}=100, \overline{\mathrm{Nu}_{\mathrm{H}, \mathrm{m}}}=22.8240,\left(\mathrm{H}_{1} / \mathrm{L}_{1}\right)_{\mathrm{o}}=2.0$;

d) $\mathrm{Re}_{\mathrm{H}}=100, \overline{\mathrm{Nu}_{\mathrm{H}}}=8.4948, \mathrm{H}_{1} / \mathrm{L}_{1}=10.0$;

e) $\mathrm{Re}_{\mathrm{H}}=1000, \overline{\mathrm{Nu}_{\mathrm{H}, \mathrm{m}}}=26.8870,\left(\mathrm{H}_{1} / \mathrm{L}_{1}\right)_{\mathrm{o}}=2.0$;

f) $\mathrm{Re}_{\mathrm{H}}=1000, \overline{\mathrm{Nu}_{\mathrm{H}}}=10.5596, \mathrm{H}_{1} / \mathrm{L}_{1}=10.0$.

The relative difference of $\overline{\mathrm{Nu}_{\mathrm{H}, \mathrm{m}}}$ also can be verified for each fin position, considering the variation of $\operatorname{Re}_{\mathrm{H}}$ (Table 2).

Table 2. Contribution of $\mathrm{Re}_{\mathrm{H}}$ variation for $\overline{\mathrm{Nu}_{\mathrm{H}, \mathrm{m}}}$ in each fin position.

\begin{tabular}{|c|c|c|c|}
\hline $\mathrm{Re}_{\mathrm{H}} \mathrm{S} / \mathrm{A}^{1 / 2}$ & 0.1 & 0.5 & 0.9 \\
\hline 10 to 100 & $44 \%$ & $36 \%$ & $3 \%$ \\
\hline 100 to 1000 & $63 \%$ & $63 \%$ & $15 \%$ \\
\hline
\end{tabular}

Table 2 makes it clear that the Reynolds number $\left(\mathrm{Re}_{\mathrm{H}}\right)$ has little influence on finned systems positioned near the upper surface of the cavity. This can also be observed by the proximity of the profiles shown in Fig. 6.

\section{CONCLUSIONS}

In the present work it was evaluated the geometry influence of a fin inserted in a lid-driven square cavity under forced convective effects in a laminar and steady flow. In order to maximize the heat transfer between the fin and the surrounding flow, the Constructal Design Method and exhaustive search was used to study the influence of some parameters in the calculation of spatial-averaged Nusselt number $\left(\overline{\mathrm{Nu}_{\mathrm{H}}}\right)$. For this, three Reynolds numbers $\left(\operatorname{Re}_{\mathrm{H}}=10,100\right.$ and 1000) were tested and the fin was moved along the upstream surface of the cavity $\left(\mathrm{S} / \mathrm{A}^{1 / 2}=0.1,0.5\right.$ and 0.9$)$ while the ratio $\mathrm{H}_{1} / \mathrm{L}_{1}$ was varied. The conservation equations of momentum and energy were solved using the Finite Volume Method (FVM).

Results of this study showed that the Reynolds number, ratio $\mathrm{H}_{1} / \mathrm{L}_{1}$ and position of the fin within the lid-driven cavity has strong influence over the Nusselt number. In particular, it is noted that the highest number of spatial-averaged Nusselt number $\left(\overline{\mathrm{Nu}_{\mathrm{H}, \mathrm{mm}}}\right)$ twice maximized was obtained for $\mathrm{Re}_{\mathrm{H}}=$ 1000 and the ideal geometry obtained for fin was $\left(\mathrm{H}_{1} / \mathrm{L}_{1}\right)_{\mathrm{oo}}=2.0$ in position $\left(\mathrm{S} / \mathrm{A}^{1 / 2}\right)_{\mathrm{o}}=0.9$. In addition, it was observed that the best geometries are those in which the temperature field has the most uniform heat distribution even with low Reynolds number. This behavior is in agreement with the optimal distribution of imperfections principle.

In this sense, among the tests carried out, it was shown that fins with a large ratio $\mathrm{H}_{1} / \mathrm{L}_{1}$ cause restrictions in the flow, which prevented the adequate heat exchange by the system. Tests on the fin position $\left(\mathrm{S} / \mathrm{A}^{1 / 2}\right)$ were also performed, where it was observed that the thermal efficiency is obtained for fins closer to the upper surface of the cavity. This behavior can be associated with the imposition of temperatures in fin and upper lid surface.

As expected, the increase in Reynolds number contributes to the increase in Nusselt numbers. However, its influence was not very effective on fins closer to the sliding surface (Tab. 2).

\section{ACKNOWLEDGEMENTS}

The authors E. D. dos Santos, L. A. Isoldi and L. A. O. Rocha thank CNPq (Brasília, DF, Brazil) for 
research Grant (Processes: 306024/2017-9, 306012/2017-0, 307847/2015-2) and for financial support in Universal project (Process: 445095/20148). The author J. F. Prolo Filho thanks FAPERGS for financial support.

\section{REFERENCES}

Aldrighi, E. S., Rodrigues, P. M., Rodriguez, B. D. A., Isoldi, L. A., Rocha, L. A. O., and Dos Santos, E. D., 2016, Constructal Design of Rectangular Fin Intruded into Different Surfaces of Forced Convective Lid-Driven Cavity Flow, International Journal of Fluid Mechanics Research, Vol. 43, No. 56, pp. 418-440.

Barros, G. M., Lorenzini, G., Isoldi, L. A., Rocha, L. A. O., and Dos Santos, E. D., 2017, Influence of Mixed Convection Laminar Flows on the Geometrical Evaluation of a Triangular Arrangement of Circular Cylinders, International Journal of Heat and Mass Transfer, Vol. 114, pp. 1188-1200.

Bejan, A., and Lorente, S. 2008, Design with Constructal Theory, John Wiley \& Sons.

Bejan, A., 2000, Shape and Structure, from Engineering to Nature, Cambridge University Press. Wiley.

Bejan, A., 2013, Convection Heat Transfer,

Bejan, A., 2016, The Physics of Life: The Evolution of Everything, St. Martins Press.

Bejan, A., and Zane, P., 2012, Design in Nature: How the Constructal Law Governs Evolution in Biology, Physics, Technology, and Social Organization, 1st edition, Doubleday.

Chamkha, A. J., Hussain, S. H., and Abd-Amer, Q. R., 2011, Mixed Convection Heat Transfer of Air Inside a Square Vented Cavity with a Heated Horizontal Square Cylinder, Numerical Heat Transfer Applications, Vol. 59, No. 1, pp. 58-79.

Dos Santos, E. D., Isoldi, L. A., Souza, J. A., Goulart, M. M., Rodrigues, M. K., Seibt, F. M., de Souza, R. V., and Rocha, L. A. O., 2013b, Constructal Design of a Rectangular Fin Intruded into Forced Convective Lid-Driven Cavity Flows, Proceeds Construction Law Conference, Vol. 1, pp. 126-134.

Dos Santos, E. D., Petry, A. P., Rocha, L. A. O., and França, F. H. R., 2013a, Numerical Study of Forced Convection Lid-Driven Cavity Flows Using Large Eddy Simulation (LES), International Journal of Energy Power Enegineering, Vol. 7, pp. 16691680.

Dos Santos, E. D., Piccoli, G. L., França, F. H. R., and Petry, A. P., 2011, Analysis of Mixed Convection in Transient Laminar and Turbulent Flows in Driven Cavities, International Journal of Heat and Mass Transfer, Vol. 54, pp. 4585-4595.

Erturk, E., and Gökçöl, C., 2006, Fourth-Order Compact Formulation of Navier-Stokes Equations and Driven Cavity Flow at High Reynolds Numbers,
International Journal for Numerical Methods in Fluids, Vol. 50, No. 4, pp. 421-436.

FLUENT, 2007, Documentation Manual, Fluent Inc.

Fontana, É., Capeletto, C. A., da Silva, A., and Mariani, V. C., 2015, Numerical Analysis of Mixed Convection in Partially Open Cavities Heated from Below, International Journal of Heat and Mass Transfer, Vol. 81, pp. 829-845.

Gibanov, N. S., Sheremet, M. A., Oztop, H. F., and Al-Salem, K., 2017, Convective Heat Transfer in a Lid-Driven Cavity with a Heat-Conducting Solid Backward Step Under the Effect of Buoyancy Force, International Journal of Heat and Mass Transfer, Vol. 112, pp. 158-168.

Hammami, F., Souayeh, B., Ben-Cheikh, N., and Ben-Beya, B., 2017, Computational Analysis of Fluid Flow Due to a Two-Sided Lid Driven Cavity with a Circular Cylinder, Computers \& Fluids, Vol. 156, pp. 317-328.

Helbig, D., Da Silva, C. C. C., Real, M. de V., Dos Santos, E. D., Isoldi, L. A., and Rocha, L.A.O., 2016, Study About Buckling Phenomenon in Perforated Thin Steel Plates Employing Computational Modeling and Constructal Design Method, Latin American Journal Solids Structures, Vol. 13, pp. 1912-1936.

Kareem, A. K., Mohammed, H. A., Hussein, A. K., and Gao, S., 2016, Numerical Investigation of Mixed Convection Heat Transfer of Nanofluids in a Lid-Driven Trapezoidal Cavity, International Communication in Heat and Mass Transfer, Vol. 77, pp. 195-205.

Lin, L. S., Chen, Y. C., and Lin, C. A., 2011, Multi Relaxation Time Lattice Boltzmann Simulations of Deep Lid Driven Cavity Flows at Different Aspect Ratios, Computers \& Fluids, Vol. 45, No. 1, pp. 233-240.

Lorenzini, G., Barreto, E. X., Beckel, C. C., Schneider, P. S., Isoldi, L. A., Dos Santos, E. D., and Rocha, L. A. O., 2017, Geometrical Evaluation of TShaped High Conductive Pathway with Thermal Contact Resistance for Cooling of Heat-Generating Medium, International Journal of Heat and Mass Transfer, Vol. 108, pp. 1884-1893.

Lorenzini, G., Biserni, C., Correa, R. L., Dos Santos, E. D., Isoldi, L. A., and Rocha, L. A. O., 2014, Constructal Design of T-Shaped Assemblies of Fins Cooling a Cylindrical Solid Body, International Journal of Thermal Sciences, Vol. 83, pp. 96-103.

Lorenzini, G., Machado, B. S., Isoldi, L. A., Dos Santos, E. D., and Rocha, L. A. O., 2016, Constructal Design of Rectangular Fin Intruded into Mixed Convective Lid-Driven Cavity Flows, ASMEJournal Heat Transfer, Vol. 138, No. 10, pp. 102501.

Nallasamy, M., and Prasad, K. K., 1977, On Cavity Flow at High Reynolds Numbers, Journal of Fluid Mechanics, Vol. 79, No. 2, pp. 391-414.

Prasad, A. K., and Koseff, J. R., 1989, Reynolds Number and End-Wall Effects on a Lid-Driven 
Cavity Flow, Physics Fluids A: Fluid Dynamics, Vol. 1, No. 2, pp. 208-218.

Prasad, A. K., and Koseff, J. R., 1996, Combined Forced and Natural Convection Heat Transfer in a Deep Lid-Driven Cavity Flow, International Journal of Heat and Fluid Flow, Vol. 17, No. 5, pp. 460-467.

Razera, A. L., Fagundes, T. M., Seibt, F. M., Da Fonseca, R. J. C., Varela, D. J., Ortiz, P. R. B., Coelho, F. R., Lessa, L. Z., Schmidt, A., Furtado, G. M., Dos Santos, E. D., Isoldi, L. A., and Rocha, L. A. O., 2016, Constructal Design of a Triangular Fin Inserted in a Cavity with Mixed Convection LidDriven Flow, Defect and Diffususion Forum, Vol. 372, pp. 188-201.

Rodrigues, M. K., Brum, R. da S., Vaz, J., Rocha, L. A. O., Dos Santos, E. D., and Isoldi, L. A., 2015, Numerical Investigation About the Improvement of the Thermal Potential of an EarthAir Heat Exchanger (EAHE) Employing the Constructal Design Method, Renewable Energy, Vol. 80, pp. 538-551.

Sivasankaran, S., Sivakumar, V., and Hussein, A. K., 2013, Numerical Study on Mixed Convection in an Inclined Lid-Driven Cavity with Discrete Heating, International Communications in Heat and Mass Transfer, No. 46, pp. 112-125.

Versteeg, H. K., and Malalasekera, W. 2007, An Introduction to Computational Fluid Dynamics: the Finite Volume Method, Pearson Education.

Vieira, R. S., Petry, A. P., Rocha, L. A. O., Isoldi, L. A., and Dos Santos, E. D., 2017, Numerical Evaluation of a Solar Chimney Geometry for Different Ground Temperatures by Means of Constructal Design, Renewable Energy, Vol. 109, pp. 222-234.

Xie, G., Song, Y., Asadi, M., and Lorenzini, G., 2015, Optimization of Pin-Fins for a Heat Exchanger by Entropy Generation Minimization and Constructal Law, Journal of Heat Transfer, Vol. 137, No. 6, pp. 061901. 